\title{
Dental Student's Education in the ERA of Pandemic: From Reality to Virtuality: Lessons to be Learned
}

\author{
Rola Habashneh ${ }^{1 *}$, Anas Alibrahim², Tahani AbuAlteen ${ }^{3}$, Wiam Hamadah ${ }^{4}$ and Yousef Khader \\ ${ }^{1}$ Professor, Department of Preventive Dentistry, Jordan University of Science and Technology, Jordan \\ ${ }^{2}$ Assistant Professor, Department of Prosthodontics, Jordan University of Science and Technology, Jordan \\ ${ }^{3} \mathrm{M}$ Clin Dent Prostho, Private Practice, Jordan \\ ${ }^{4}$ Graduate Student, Department of Periodontics and Preventive Dentistry, Jordan University of Science and Technology, \\ Jordan
}

${ }^{5}$ Professor, Department of Epidemiology and Public Health, Jordan University of Science and Technology, Jordan

\begin{abstract}
Background: The pandemic of coronavirus disease 2019 [COVID-19] has become a major public health challenge for many countries around the world. The global lockdown of educational institutions is going to cause major disruption to students' learning and cancellation of their yearly assessments. Dental students are particularly at risk, due to the possibility of aerosols produced in many dental procedures that were suggested as a way of transmission of the COVID-19 virus. Shifting to online learning is needed in this era.
\end{abstract}

Objectives: This article aims to review the online learning experience, the effectiveness of tele-dentistry and the importance of implementing dental virtual simulation in preclinical and clinical courses during pandemics. Some suggestions are also provided to widen communication and creativity in the education system. The limitations of online learning and suggested solutions are also discussed.

Materials and methods: Two independent investigators conducted an electronic comprehensive search of PubMed/ MEDLINE for articles published between 1993 and 2020, using the following search terms: "online education"; "Teledentistry"; "Education during pandemics"; "Virtual dentistry"; "COVID-19 reshaping education"; and "Dental E-learning." Studies were selected and classified as included or excluded based on the title and abstract of the articles by the 2 researchers, working independently. Articles included were published in English, related to dentistry and online education. Articles excluded were not published in English or related to conventional education. It was not possible to analyze included articles, therefore we decided to do narrative review only. Authors' points of view and suggestions were also added to shed light on the online learning experience and understand its quality and effectiveness during pandemics.

Results: from 150 articles reviewed, only 30 articles were found to qualify for inclusion. All included articles discussed online education based on experience of authors and provided some suggestions so that online learning experience becomes more effective. All included articles found that online education is a useful tool to be invested at times of pandemics and that it needs to be empowered and improved by schools and universities.

Conclusions: Being successful in riding the wave will take dental learning and teaching into a new era. In the future, every dean and faculty member will understand that online education is not only a potential source for new revenue. Instead, online education will be recognized as an essential core to every educational plan for institutional resilience and academic continuity.

Clinical relevance: After this crisis ends, the innovative characteristic of online dental education needs to be evaluated in terms of quality and effectiveness. As for dentistry, online education alone might not be the best solution in the longterm, but it can be of great benefit to enhance students' learning and skills in combination with traditional teaching.

Keywords

Dentistry, Students, COVID-19

\section{Introduction}

As the world is fighting against the COVID-19 outbreak, and according to UNICEF monitoring in April-2020, 1.725 bil- lion students are affected by schools' closure in response to pandemic. Apparently, 186 countries are applying nationwide closures while 8 countries are applying local closures, affecting almost $98.5 \%$ of the world's student population [1]. Social 
distancing is the key element in slowing the outbreak, which has created a new world order requiring a shift in perspective and necessitating thinking in different ways to continue the teaching cycle - learning goes on, displaced, but not discontinued. Classes are moving online, all the participants present at the same time, yet located remotely [2].

It can be noticed that COVID-19 crisis has given the educational systems some advantages that were not recognized before. The role and participation of the individual in the education cycle was improved, every student became responsible for his own learning, and the professors became the guides to create something out of nothing and encourage creativity and innovation. The students have a chance to find their strengths rather than fight their weaknesses. Also, it is noticeable that there is less emphasis on grading and more on being supportive and caring, and finding the spaces where all can work together to discover meaningful and joyful learning.

The teaching of dentistry depends mainly on practical work, either in the labs on phantom heads or in the clinics on real patients. Pre-clinical simulation on phantom heads provides the students with motor skills and procedural knowledge that prepares them for clinical patient care. It also provides them with control of resources and awareness of the time needed to perform different dental procedures, allows them to learn dental procedures in isolation from the patient and the complexities of the clinical environment, and also allows them to practice dental skills prior to working on real patients and this provides some assurance of clinical ability for safe dental procedures [3].

During the COVID-19 pandemic, dental students are particularly at risk, due to the possibility of aerosols produced in many dental procedures that are suggested to be a way of transmission of the COVID-19 virus [4]. Also, it is now believed that interpersonal transmission of COVID-19 virus occurs mainly via respiratory droplets and contact transmission [5].

COVID-19 has been demonstrated to remain aerosolized for 3 hours after contamination and on plastics and stainless steel for up to 72 hours. This makes the dental community a relatively high-risk population [6]. To minimize the risk circle of transmission, dental schools are expected to design training dental clinics in a more spacious area, isolate the dental clinics so that each clinic is independent in design, provide environmental controls such as: different pressure ventilation, filtration systems and air purifiers, with emphasis on quality of personal protective equipment [PPE] to reduce exposure to communicable diseases.

The question here is how the teaching plan will be modified to keep going on despite the global limitations going around. According to the March 16 statement from ADA President Chad P. Gehani. "The ADA is deeply concerned for the health and well-being of the public and the dental team and recommends dentists nationwide to postpone elective procedures" [7]. Thus, there is a reduction in elective procedures available for these students to gain experience, even if the above risks are addressed.

\section{Tele Dentistry}

Tele dentistry might be a valid solution. It refers to the use of online tele-health systems in delivering health and dental services. The term "Tele-dentistry" was used in 1997, when Cook defined it as "... the practice of using video-conferencing technologies to diagnose and provide advice about treatment over a distance" [8]. Formal online education can be divided into two main categories: Web-based self-instruction and interactive videoconferencing. The Web-based self-instruction educational system contains information that has been developed and stored before the user accesses the program [9]. The advantage of Web based self-instruction is that the user can control the pace of learning and can review the material as many times as he or she wishes $[9,10]$, while interactive videoconferencing includes both a live interactive videoconference [with at least one camera set up where the patient's information is transmitted]. The advantage of this educational style is that the user [typically the patient's health care provider] can receive immediate feedback.

In addition, Tele-dentistry is used widely and less formally at the grass-roots level. Dental chat rooms are available through numerous dental organizations and study clubs, as well as through individual practitioners who exchange information on a variety of topics [11].

A new education framework is suggested according to Tele-dentistry principle, which constitutes of Tele-teaching, Tele-training and Tele-support (Figure 1).

\section{Tele teaching}

Online meeting rooms should be provided by each dental

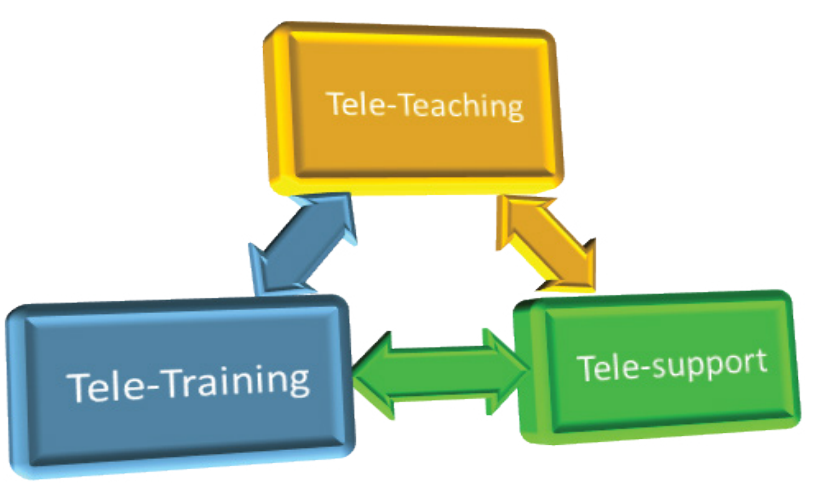

Figure 1: Tele-dentistry framework.

*Corresponding author: Prof. Rola Al Habashneh, Faculty of Dentistry, Departments of Preventive Dentistry, Jordan University of Science and Technology, P.O. Box (3030), Irbid, 22110, Jordan

Accepted: October 08, 2020

Published online: October 10, 2020

Citation: Habashneh R, Alibrahim A, AbuAlteen T, et al. (2020) Dental Student's Education in the ERA of Pandemic: From Reality to Virtuality: Lessons to be Learned. Archives Oral Maxillofac Surg 3(1):62-68 
school. They should be designed to be available for all students and within time limits. Online lectures, case studies, and problem-based learning tutorials should be adopted. In addition, teachers should be available and encourage the students to gain the best results from distance learning and to engage in self-learning and make full use of online resources.

\section{Tele training}

The importance of clinical training in dental practice can't be underestimated. While respecting the guidelines of health authorities and maintaining social distancing, the numbers of students attending the clinics can be reduced, and they can be encouraged to share their clinical experiences and learning among each other. In this way, the students all receive clinical information and $x$-rays on multiple cases examined and treated by a selected number of students who attend the clinic that day. This gives all students a chance to discuss and learn daily from cases even if from a distance, which will ensure maintenance of their clinical training and experience. The clinical experiences could be recorded for viewing by those unable to work in the clinic on a particular day due to COVID restrictions.

\section{Tele support}

It is proposed that students would get effective support and guidance from their teachers from a distance. Additionally, by making the learning system group based, students would support each other when learning together.

Moving to online learning by using the internet needs speed, cost-effectiveness, and sufficient efforts to maintain and sustain a course [11]. In addition, effective blending of e-learning platforms and technologies are needed to enable educators to provide students with effective and useful learning opportunities. In a study by Harden, E-learning was considered the most important tool in graduate and postgraduate medical education delivery [12]. Additionally, most of the students belong to the millennial generation and are adapted to using technology-enhanced learning resources [13].

We are also proposing some extra tips that can be used to widen the area of communication and creativity in the education pyramid and increase the success of the e-learning experience:

1. Dental E-Learning Mobile Phones Applications: The educational sector is the third most popular category of app downloads in 2018 with an $8.5 \%$ share, after games with $25 \%$ and business apps with 9.8\% share [Apple Store Downloads, 2018] [14]. Mercedes and Radel in 2016 examined the use of smartphone technologies in enabling professors to set weekly quizzes that were completed on the student's smartphone before classes commenced. Their research concluded that using the mobile application increased participation and encouraged continuous learning [15].

Accordingly, we suggest designing an updated learning application that authorizes discussion chat rooms, online webinars, sharing multimedia learning folders, messages, and assignments for each course, with the possibility to save any given webinar or notes for future use. This one application will be considered a definite teaching resource and all students can access materials flexibly and participate in sharing materials. Ideally the application would send alerts and notifications to all users once new items are shared. University faculties should investigate students' ability to have electronic resources to benefit from such applications and help those who cannot afford to have any.

2. Digital Local Educational Magazine: Students are more interested in following news through smart devices, by which educators can place customized class content in a more interesting way in their hands. Digital magazines released on a weekly or monthly basis, can become an interesting study resource. Digital magazines that allow for searching online for publications and provide the ability to easily share information between colleagues can increase the students' level of engagement with class content. Students can be more involved in collecting new experiences and information. Also, magazines can encourage students to get into research and share what they find for their colleagues which will be a new interesting experience for them.

According to Luna-Nevarez, et al., in 2018 the time spent on the digital magazine was very productive, engaging with class content and sparked students' curiosity and interest. It seems that students enjoy the learning experience provided by the digital magazine and find it useful [16].

3. Dental Teaching Radio Stations: Students can get extra information from radio stations. They can widen their knowledge and help them in getting new ideas. They can make them think out of the box not only in their basic theory routine. Also, radio is capable of delivering high quality educational programming to diverse audiences located across broad geographical expanses - all at a low per unit production cost [17]. Studies conducted by the Open University UK have demonstrated that, when used as a supplementary learning tool, radio benefits weaker students [18]. It can play a role in inspiring them to learn more. The Agency for International Development has shown radio to be more cost-effective and capable of exerting greater learning effects than textbooks or teacher-led education [18].

The role of radio in shaping the society and providing information and education is significant, thus using the advantages of educational broadcasting for improving education and enrichment purposes is proposed and archiving the radio broadcasts as podcasts for those who can't listen at a particular time is advised.

4. Keep groups small: Participation is required in discussions, so every batch should be subdivided into small groups. The students have a strong preference for small group sessions and for the "small group one case plus peer-teaching" format. It is very clear that this format produces at least the perception of higher learning gain, more goals reached and more active participation [19]. The dynamics of group size is an important component of group work. A small group is often considered to consist of three or more people [20]. Groups of two are called dyads and are not encouraged for group work because there are not a sufficient number of individuals to generate creativity and diversity of ideas. Three or 
four members were suggested to be more appropriate. Larger groups decrease each members' opportunity to participate and often results in some members not actively contributing to the group [21].

Each group should be guided by a co-advisor. The co-advisor manages the discussion rooms and guides them in searching and reaching the answers smoothly. It would be great if weekly clinical scenario discussions are scheduled to teach the students how to use their theoretical information in practical thinking.

5. Encourage multimedia projects: Projects which allow students to combine different types of media [text, audio, video, pictures, graphics, etc.] into one presentation offer an opportunity for participants to actively engage and understand the gathered information. In some cases, what students learn by using multimedia is different from what they learn prior to the use of multimedia. Students may participate in simulated life-experiences, make decisions, and learn the consequence. They can experiment with data and scientific equipment which was not accessible prior to multimedia use [22].

6. Encourage group efforts: The variety of backgrounds and experiences make group discussions rich in information.

Many people cringe and groan when told that they will need to work in a group. This phenomenon is called "grouphate." One way to overcome grouphate is to form realistic expectations of group work [23]. According to Beebe and Masterson, there are advantages and disadvantages to working in a group. By understanding the benefits and potential pitfalls, a group can capitalize on the virtues of group work and minimize the obstacles that hinder success [20].

Students working in small groups have a tendency to learn more of what is taught and retain it longer than when the same material is presented in other instructional formats $[24,25]$. Also, teamwork is highly valued by employers. When NACE asked employers participating in its Job Outlook 2018 survey which attributes-beyond a strong GPA-they most value, employers indicated that problem-solving skills and an ability to work in a team are the most desired attributes and are of equal importance $[24,26]$.

\section{Online vs. traditional teaching}

It is worth mentioning that Broudo and Walsh in 2002 stated that online learning in medicine and dentistry provides important adjuncts to all the teaching components [27]. Multidirectional thinking, working and discussing brightens up new ideas which takes the students into the extraordinary and makes them more mindful.

A study suggested to shift teaching strategies from didactic traditional teaching and recommended a combination of other methods such as problem based learning [PBL], videos, quizzes and group discussions to cater the needs of adults' learning, change teaching direction from gaining knowledge only to critical thinking and clinical reasoning, and make the whole learning experience more interesting, interactive and effective .In this study, preferences of students on recent teaching methods were assessed. Students found videos to be the most effective followed by questions, PBL, discussion, case study lecture, power point presentation [PPT], quiz, group work, role play and debate, respectively [28].

Mind-maps were suggested as an effective teaching method when applied to theoretical material [29]. A study evaluated the effectiveness and persistence of knowledge between two teaching methods: mind-maps and traditional teaching among dental undergraduate students. Mind-maps were found to be more effective [30].

A drawback of traditional preclinical laboratory teaching in the dental school is that students find it difficult to integrate theoretical knowledge and practical skills and this results in fragmentation of knowledge. Interactive multimedia teaching tools can be added to dental education to improve students' exposure to the art of dentistry [31].

A MEDICOL [Medicine and Dentistry Integrated Curriculum Online] site was developed for students in British Columbia University to be used in the distant learning process. This site provides different web-based resources that aim to provide many educational benefits: 1) Observe progress of students and display information about given courses such as time-tables, objectives, handout materials, images, references, assignments, and evaluations, 2) Encourage student-student and student-lecturer interactions [through emails], and 3) Present self-directed learning components, including weekly quizzes that deliver feedbacks about effectiveness of online learning. More than $90 \%$ of students used the MEDICOL site regularly and found it helpful [27].

\section{What To expect from students?}

Classroom education is known to be teacher-centered requiring passive learning by the students while online education is often student-centered requiring active learning by the students [32].

Technical capacities of students must be enhanced to meet the requirements of online education. This includes communication skills and teamwork. Online learning will be particularly helpful for students who struggle with engaging in the traditional learning environment as social presence is constricted [33]. This might enhance the self-esteem of students and encourage them to participate in group discussions with confidence, which will be reflected in their effective handling of patients' emotions and ethical professionalism [34].

On the other hand, traditional classroom learning with face-to-face interaction is a well-established modality for some students who are opposed to change and view online learning negatively maybe because they are technophobes, or value organic student-teacher bonding and thrive sitting in a classroom taking notes rather than sitting at a computer absorbing data [35].

Online teaching will guide the students to benefit from the available online resources. This will encourage them to implement evidence-based dentistry in their clinical treatment planning. The students could meet periodically to present newly completed treatment options based on evi- 
dence-based dentistry to their peers [36]. They will start to link clinical expertise, the patient's preferences, and the most current, clinically relevant evidence, which can help close the gap between clinical research and real-world dental training.

At last, students may adapt to online education as more universities are employing computer-based training and webbased courses, after all, many students grew up cultivating and navigating their social lives on screens and keyboards [32].

\section{Virtual teaching? Is it a thing?}

Tactile skills of dentists are important for best dental care delivery. Dental virtual simulation can be an important tool to improve manual dexterity of dental students especially during pandemics to minimize their interactions with patients. Virtual reality simulators can bridge the gap in dental education enabling students to improve their tactile sensation of tissues and assess their competency. It also enables objective evaluation of time taken to complete the procedure, competence of movements and percentage of errors made [37].

The question here is "would virtualization be at the cost of quality of learning?"

One study tried to address this question by evaluating the influence of virtual technology on students' learning and motivation and found that students using virtual simulators got higher grades and better motivational levels than students of traditional teaching methods [38].

If the online learning experience reaches the expected quality and effectiveness, should it be the default approach, removing the face-face approach along with its expenses. In fact, online learning is not a cheap option, as proper curriculum design and technical support with appropriate funding and staffing is still needed [39].

\section{Expected limitations for Tele-education and sug- gested solutions}

As discussed before, the number of students has an impact on the results of online teaching. Dental school thinking of an online teaching plan should consider accepting a lower number of students to raise the effectivity of their E-learning or modifying their plan to accommodate the numbers they accept yearly.

A suggested modification is increasing the number of training years and dividing groups of students according to that. More credit hours should be given for the increased laboratory training and stimulatory teaching sessions.

In addition, dental schools should set the curriculum including use of technological studying methods from first year and add more in them gradually including planning joint courses with the faculty of technology.

Another challenge is that more skills are required from the instructors for Tele-dentistry education courses because they need to have both teaching experience and technological skills [40]. Educators are advised to manage expectations and performance of students in the online learning experience, they are also advised to be flexible in students' assessment, to master the use of digital platforms offered by the university and to create a supportive and inclusive environment for students who enjoy virtual learning and those who do not.

For a good-quality online learning experience, a curriculum design focused on engagement strategies of students in the online environment is needed [41]. This includes enhancing social learning connections with lecturers and colleagues, encouraging feedback about E-learning methods and using smart technologies and digital learning tools. Thinking of how and what to deliver is critical since teaching the conventional lecture as it is online, reduces the engagement of students. For example, if a 1-hour lecture recording is uploaded online, students might not engage as needed and fail to gain the proper knowledge. Reports showed that students watching long lecture recordings online might get easily distracted by social media browsing [42] which cannot be noticed by the educator. It is suggested that lectures which can be presented live in 1 hour, should be re-designed into a series of 5-7 minutes videos when presented online so that students engage and focus on one or two concepts at a time, integrating mini-quizzes, case studies, and interactive live discussions within the task [43].

Educators need to bear in mind that many students will report feelings of disconnectedness, missing teacher immediacy, and loss of interpersonal interactions they are used to have in the traditional learning environment once transitioned to online learning [44]. This means that more efforts should be made for them to keep the social connection even if at a distance.

Additionally, some students are questioning whether online learning should cost the same as face-face learning or not [45]. Teaching modifications, system changes and infection control upgraded set ups may raise the yearly fees required from the students. To overcome this, the university may offer the students internal jobs in labs or libraries so they can afford to cover the required changes in fees and get more involved in technical teaching and studying experience.

A key challenge to be mentioned is finding an assessment method that assesses to the same quality and whether the multiple-choice style will remain efficient or not for a sustained online approach especially with concerns about cheating. Offering in-person e-assessments might limit the cheating opportunities [46].

Equality of online learning equipment and access to good internet connectivity for all students are essential for learning continuity. Poor download speeds limit the potential of internet resources [especially videos, sound and other large downloads] to benefit students [47]. Also, unexpected interruptions can be an obstruction for planned online courses. It is crucial that in times like these, human tutoring can be facilitated through online and digital means if they are equally accessible to everyone. As a solution, each dentistry college must provide the students with the suitable technical resources and sufficient internet packages to be available as a part of the upgraded online plan. 
Citation: Habashneh R, Alibrahim A, AbuAlteen T, et al. (2020) Dental Student's Education in the ERA of Pandemic: From Reality to Virtuality: Lessons to be Learned. Archives Oral Maxillofac Surg 3(1):62-68

\section{Conclusion}

Being successful in riding the wave will take dental learning and teaching into a new era. Some dental colleges and universities were not delivering any online education preCOVID-19. These will all change post-COVID-19. In the future, every dean and faculty member will understand that online education is not only a potential source for new revenue but an essential core to every educational plan for institutional resilience and academic continuity. After this crisis ends, the innovative characteristic of online dental education needs to be evaluated in terms of quality and effectiveness. As for dentistry, online education alone might not be the best solution in the long-term, but it can be of great benefit to enhance students' learning and skills in combination with traditional teaching.

\section{References}

1. (2020) COVID-19 Educational disruption and response. UNESCO.

2. Wilder-Smith A, Freedman DO (2020) Isolation, quarantine, social distancing and community containment: Pivotal role for old-style public health measures in the novel coronavirus (2019nCoV) outbreak. J Travel Med 27.

3. Fugill M (2013) Defining the purpose of phantom head. Eur J Dent Educ 17: e1-e4.

4. Wang J, Du G (2020) COVID-19 may transmit through aerosol. Ir J Med Sci 24: 1-2.

5. The Chinese Preventive Medicine Association (2020) An update on the epidemiological characteristics of novel coronavirus pneumonia (COVID19). Zhonghua Liu Xing Bing Xue Za Zhi 41: 139-144.

6. Halepas S, Ferneini EM (2020) A Pinch of Prevention is Worth a Pound of Cure: Proactive Dentistry in the Wake of COVID-19. J Oral Maxillofac Surg 78: 860-861.

7. https://www.ada.org/en/publications/ada-news/2020-archive/ march/ada-recommending-dentists-postpone-elective-procedures

8. Cook J (1997) ISDN video conferencing in postgraduate dental education and orthodontic diagnosis. Learning Technology in Medical Education Conference 1997 (CTI Medicine) 111-116.

9. Johnson LA, Wohlgemuth B, Cameron CA, et al. (1998) Dental interactive simulations corporation (DISC): simulations for education, continuing education and assessment. J Dent Educ 62 919-928.

10. Johnson L, Schleyer T (1999) Development of standards for the design of educational software. Standards Committee for Dental Informatics. Quintessence Int 30: 763-768.

11. JW Chen, MH Hobdell, K Dunn, et al. (2003) Teledentistry and its use in dental education. J Am Dent Assoc 134: 342-346.

12. Harden RM (2006) Trends and the future of postgraduate medical education. Emerg Med J 23: 798-802.

13. Pickering JD, Swinnerton BJ (2019) Exploring the dimensions of medical student engagement with technology-enhanced learning resources and assessing the impact on assessment outcomes. Anat Sci Educ 12: 117-128.

14. Apple Store Downloads Statistics. Statista.

15. Mercedes B, Radel B (2016) Smartphones: From distraction to attraction. J Educ Technol Syst 45: 93-102.
16. Luna-Nevarez C, McGovern E (2018) On the use of mobile apps in education: The impact of digital magazines on student learning. J Educ Technol Syst 47: 17-31.

17. Couch L (1997) Digital and analog communication systems. Upper saddle river, NJ Prentice-Hall.

18. Tripp S, Roby W (1996) Auditory presentations in language laboratories. In: DH Jonassen (edn) Handbook of research for educational communications and technology, Simon \& Schuster Macmillan, New York.

19. Kooloos JGM, Klaassen T, Vereijken M, et al. (2011) Collaborative group work: Effects of group size and assignment structure on learning gain, student satisfaction and perceived participation. Med Teach 33: 983-988.

20. Beebe SA, Masterson JT (2003) Communicating in small groups. Pearson Education Inc, Massachusetts.

21. Csernica J, Hanyka M, Hyde D, et al. (2002) Practical guide to teamwork, version 1.1. College of Engineering, Bucknell University.

22. Carol Dwyer (1993) Multimedia in Education. Educ Media Int 30: 4-197.

23. Burke A (2011) Group work: How to use groups effectively. The Journal of Effective Teaching 11: 87-95.

24. Barkley EF, Cross KP, Major CH (2005) Collaborative learning techniques: A handbook for college faculty. ( $2^{\text {nd }}$ edn), JosseyBass Publishers, San Francisco.

25. Davis BG (1993) Tools for teaching. Jossey-Bass Inc, San Francisco, California.

26. https://www.naceweb.org/store/2017/job-outlook-2018/

27. BROUDO M, WALSH C (2002) MEDICOL Academic. Medicine 77: 926-927.

28. Anthony Leela, Latt Swe, Afrose Tahmina, et al. (2018) Preferred teaching methods by medical and dental students of a private university: The Students Perception. IJIRMPS.

29. Farrand P, Hussain F, Hennessy E (2002) The efficacy of the 'mind map' study technique. Med Edu 36: 426-431.

30. Bhat Padma, Jayachandra MY, Vg Krishna, et al. (2019) Mind mapping-a learning strategy!! among dental studenTS: A Comparative Study. Int J Sci Res 8: 1-3.

31. Sharma S, Vijayaraghavan V, Tandon P, et al. (2012) Dental education: Current scenario and future trends. J Contemp Dent Pract 13: 107-110.

32. Paul J, Jefferson F (2019) A Comparative analysis of student performance in an online vs. face-to-face environmental science course from 2009 to 2016. Front Comput Sci.

33. Gillett-Swan J (2017) The challenges of online learning: Supporting and engaging the isolated learner. J Learn Design 10: 20-30.

34. Driscoll A, Jicha K, Hunt AN, et al. (2012) Can online courses deliver in-class results? A comparison of student performance and satisfaction in an online versus a face-to-face introductory sociology course. Am Sociol Assoc 40: 312-313.

35. Roval AP, Jordan HM (2004) Blended learning and sense of community: A comparative analysis with traditional and fully online graduate courses. Int Rev Res Open Dist Learn 5.

36. Werb Sarah B, Matear David W (2004) Implementing evidence-based practice in undergraduate teaching clinics: A systematic review and recommendations. J Dent Educ 68: 995-1003. 
Citation: Habashneh R, Alibrahim A, AbuAlteen T, et al. (2020) Dental Student's Education in the ERA of Pandemic: From Reality to Virtuality: Lessons to be Learned. Archives Oral Maxillofac Surg 3(1):62-68

37. Sivaranjani Gali, Patil Archana (2018) The technology of haptics in dental education. JDOR 14: 70-75.

38. Abdel-Maksoud, Nahed F (2018) When virtual becomes better than real: Investigating the impact of a networking simulation on learning and motivation IJEP 6: 253-270.

39. Dreon O, Shibley IA Jr, Wilson TD (2019) The power of blended learning in the sciences. $1^{\text {st }} \mathrm{Ed}$. Ann Arbour, MI: The Part-Time Press.

40. Spallek H, Pilcher E, Lee JY, et al. (2002) Evaluation of web based dental CE course service. J Dent Educ 66: 393-404.

41. Martin F, Bolliger DU (2018) Engagement matters: Student perceptions on the importance of engagement strategies in the online learning environment. Online Learn Environment 22: 205222.

42. Zureick AH, Burk-Rafel J, Purkiss JA, et al. (2018) The interrupted learner: How distractions during live and video lectures influence learning outcomes. Anat Sci Educ 11: 366-376.

43. Mayer RE, Moreno R (2003) Nine ways to reduce cognitive load in multimedia learning. Educ Psychol 38: 43-52.

44. Slagter van Tryon PJ, Bishop MJ (2009) Theoretical foundations for enhancing social connectedness in online learning environments. Dist Educ 30: 291-315.

45. Turner C, Rowan C (2020) University students campaign for refund as they say remote learning should not cost $£ 9,250$-peryear. The Telegraph.

46. Evans DJR, Bay BH, Wilson TD, et al. (2020) Going virtual to support anatomy education: A STOP GAP in the midst of the Covid-19 Pandemic. Anat Sci Educ 13: 279-283.

47. Williams CD, Pitchforth EL, O'Callaghan C (2010) Computers, the internet and medical education in Africa. Med Educ 44: 485-488. 